\title{
A Perspective on the Flame Spray Synthesis of Photocatalyst Nanoparticles
}

\author{
Wey Yang Teoh \\ Clean Energy and Nanotechnology (CLEAN) Laboratory, School of Energy and Environment, City \\ University of Hong Kong, Tat Chee Avenue, Kowloon, Hong Kong; E-Mail: wyteoh@ cityu.edu.hk; \\ Tel.: +852-3442-4627; Fax: +852-3442-0688.
}

Received: 3 June 2013; in revised form: 6 July 2013 / Accepted: 8 July 2013 /

Published: 31 July 2013

\begin{abstract}
The synthesis of functional nanoparticles via one-step flame spray pyrolysis (FSP), especially those of catalytic nature, has attracted the interests of scientists and engineers, as well as industries. The rapid and high temperature continuous synthesis yields nanoparticles with intrinsic features of active catalysts, that is, high surface area and surface energetics. For these reasons, FSP finds applications in various thermally inducible catalytic reactions. However, the design and synthesis of photocatalysts by FSP requires a knowledge set which is different from that established for thermal catalysts. Unknown to many, this has resulted in frustrations to those entering the field unprepared, especially since FSP appears to be an elegant tool in synthesising oxide nanoparticles of any elemental construct. From simple oxide to doped-oxide, and mixed metal oxide to the in situ deposition of noble metals, this Perspective gives an overview on the development of photocatalysts made by FSP in the last decade that led to a better understanding of the design criteria. Various challenges and opportunities are also highlighted, especially those beyond simple metal oxides, which perhaps contain the greatest potential for the exploitation of photocatalysts design by FSP.
\end{abstract}

Keywords: flame synthesis; photocatalysis; semiconductor; nanoparticle; mixed oxides

\section{Flame Spray Synthesis of Nanoparticles}

Flame aerosol synthesis is an established manufacturing technique for producing commodity nanoparticles at the industrial scale. Its modern history stretches as far back as the 1940s, when Degussa (now Evonik) patented and manufactured Aerosil ${ }^{\circledR}$ fumed $\mathrm{SiO}_{2}$ from the flame hydrolysis of 
$\mathrm{SiCl}_{4}$ vapour [1]. Today, a variety of particles are produced using the flame technique, in descending order of production mass: carbon blacks, pigmentary $\mathrm{TiO}_{2}, \mathrm{ZnO}$, fumed $\mathrm{SiO}_{2}$ and optical fibers with an estimated annual production on the order of million metric tons [2]. Importantly, $\mathrm{TiO}_{2}$ nanoparticles manufactured by Evonik under the brand name of P25 has survived the test of time as the gold standard photocatalyst. Similarly to the original Aerosil process, these photocatalytic particles are manufactured by the hydrolysis of $\mathrm{TiCl}_{4}$ vapour in an oxy-hydrogen flame. Although the target market was geared towards commodity pigments, since 1980s, $\mathrm{P} 25 \mathrm{TiO}_{2}$ nanoparticles have been routinely applied to various photomediated processes, namely, purification of air and water $[3,4]$, organic syntheses [5], water splitting [6] and dye-sensitised solar cells [7]. The high intrinsic activity of this reference photocatalyst has proven difficult to be overtaken by many other designer $\mathrm{TiO}_{2}$ particles. So it is intriguing that the origin of high activity of P25 is still a subject of intense investigation [8-10].

As a modern variation of flame synthesis, many research groups [11-14], including us [15], have been actively developing the flame spray pyrolysis (FSP) for a plethora of applications. Unlike the conventional vapour-fed flame synthesis (VFS) [13] used to manufacture P25 $\mathrm{TiO}_{2}$, the FSP features the direct combustion of highly exothermic liquid precursor sprays. Whereas metal precursors are thermally vaporised prior to feeding into the VFS flame, here, the FSP makes use of the high flame temperature to vaporise the liquid precursor at the upstream of the flame itself. There are many advantages of pursuing the latter path, that is, switching from vapour to liquid precursors. They include circumventing the challenges of handling toxic metal carbonyls or corrosive metal halides vapours during the precombustion process, and/or by products such as $\mathrm{HCl}$ from the hydrolysis of metal halides in the post-combustion process. More importantly, a much wider choice of metal precursors can be made available in FSP since it is less restricted by the requirement of volatile precursors necessary for VFS. In fact, the current selection of metal precursors for FSP is so wide the reported metal precursors cover almost half of all the elements in the periodic table [15].

For formation of homogeneous particles, as that in VFS, highly exothermic liquid precursors are essential during FSP to ensure that the metal precursors are completely vaporised within the flame. Once they exist as metal/metallorganic vapours, the desired metal oxide particles can be formed via the vapour-to-particle route, a process similar to a VFS (Figure 1f, and to be explained below) $[1,16]$. Direct utilisation of the lowest cost precursors such as nitrates and acetates are unsuitable for FSP due to their low combustion enthalpies as they may not even vaporise completely in the flame. Nevertheless, formulations exist requiring only basic reflux and distillation, to convert them into highly exothermic organometallics [16-18]. Metal alkoxides, 2-ethylhexanoates, acetylacetonates are generally preferred, since they also have low boiling points relative to that of the solvent medium [15]. This allows the vaporisation of metal precursors prior to the full vaporisation of the organic solvent at the early stage of the flame combustion [19]. Once metal vapour is formed, the remaining downstream process includes the sequential nucleation as metal or metal oxides, sintering and coalescence, aggregation and agglomeration (Figure 1f) [20,21]. In the cases of non-volatile precursors with low combustion enthalpy (sometimes endothermic, e.g., metal nitrates), this may lead to the formation of solid precursor residue from each spray droplet, much like a spray drying process (i.e., droplet-to-particle route). This would lead to large and overall inhomogeneous particles.

One can see that in FSP, the amount of metal elements can be effectively conserved within the flame and further condensed as the product particles. In other words, the stoichiometry of the resultant particles 
is fully reflected as originally designed in the liquid precursors. This feature, coupled with the wider availability of liquid precursors, has to date facilitated the rapid expansion of flame syntheses of complex functional nanoparticles consisting of two or more metal elements. They range from doped metal oxides, (Al-doped $\mathrm{CeO}_{2}$ [22], Cu-doped $\mathrm{Ce}_{x} \mathrm{Zr}_{1-x} \mathrm{O}_{2}$ [23-25], Sn-doped $\mathrm{ZnO}$ ) [26]; decoration of metal deposits on oxide supports $\left(\mathrm{Ag} / \mathrm{TiO}_{2}\right.$ [27], $\mathrm{Pt} / \mathrm{Al}_{2} \mathrm{O}_{3}$ [28], $\mathrm{Rh} / \mathrm{Al}_{2} \mathrm{O}_{3}$ [29], $\left.\mathrm{Pd} / \mathrm{Fe}_{2} \mathrm{O}_{3}\right)$ [30]; surface encapsulation $\left(\mathrm{SiO}_{2} / \mathrm{ZnO}\right.$ [31], $\mathrm{Al}_{2} \mathrm{O}_{3} / \mathrm{Ce}_{0.7} \mathrm{Zr}_{0.3} \mathrm{O}_{2}$ [32], $\mathrm{SiO}_{2} / \mathrm{Fe}_{2} \mathrm{O}_{3}$ [33,34], $\mathrm{TiO}_{2} / \mathrm{CeO}_{2}$ [35], C/Pt [36]); mixed metal oxides $\left(\mathrm{LiFe}_{5} \mathrm{PO}_{8}\right.$ [37], $\mathrm{LaCoO}_{3}$ [38], $\left.\mathrm{SrTiO}_{3}\right)$; and heterojunctions $\left(\mathrm{BaCO}_{3} / \mathrm{Al}_{2} \mathrm{O}_{3}\right)$ [39]; to solid solutions $\left(\mathrm{Ce}_{x} \mathrm{Zr}_{1-x} \mathrm{O}_{2}\right)$ [40]. Here, the flexibility of designing particles in a mix-and-match and scalable manner, creates an emerging market for flame-made materials, as it diversifies beyond commodity-focused simple oxides. Niche functional nanoparticles with high market values, for instance, $\mathrm{Ta}_{2} \mathrm{O}_{5} / \mathrm{SiO}_{2}$ dental fillers are lucrative and commercially very attractive. Despite being only at the dawn of a very exciting frontier in high-tech applications, heterogeneous thermal catalysis is currently leading in terms of capitalising the versatility of the FSP in synthesising various types of oxide catalysts [41]. By comparison, the extent of photocatalysts exploration by FSP has been somewhat limited. This arises from the different sets of design requirements for high efficiency photocatalysts, where the most frequently encountered issue in flame-made photocatalysts is the high defects content which acts as charge trapping or recombination centres.

Whilst the extremely short residence time of flame particles formation (typically in the range of milliseconds, that is, from the liquid precursor spray right up to agglomerated particles leaving the flame), was particularly advantageous in fabricating nanoscale particles, the time spent by the aerosol particles at high temperature flame zone was simply too short for sufficient defects healing to take place $[42,43]$. This is in contrast to the syntheses by solid-state sintering, where materials are typically subjected to prolonged high temperature exposure $(>1273 \mathrm{~K},>6 \mathrm{~h})$ to yield oxide crystals with minimum defects as necessary for applications in superconductors and solar water splitting [44]. That is not to say the flame-made particles are amorphous, in fact, these as-prepared particles are often highly crystallined single crystals when observed under high-resolution transmission electron microscopy (HRTEM) and X-ray diffraction (XRD) [45]. Rather, these particles are populated by high-density atomic defects, which can only be observed by certain molecular probes or reactions, or other specialised spectroscopic techniques.

It is easy to understand that the surface defects are advantageous for thermal catalytic reactions since these are the surface energetic sites. In some cases, foreign dopants are deliberately introduced during flame synthesis to induce additional surface defects to the crystals in order to improve catalytic efficiencies [22]. As photocatalysts however, these otherwise active sites become the electron-hole pair charge trapping (deep traps) and recombination centres. In other words, the detrimental effect of charge recombination overwhelms the benefits of surface energetics. The design of high-energy reactive facets with minimal charge recombination centres would be an ideal photocatalyst in this case, but this has so far only been demonstrated by wet preparation techniques [46]. Hereby in this Perspective, we revisit some case studies in the development of photocatalysts by FSP, highlighting the progress as well as the scientific and technical challenges in bridging the FSP and photocatalysis. 


\section{Simple Metal Oxide Photocatalysts_-Starting from the Basics}

In 2005, we reported our first attempt to synthesise $\mathrm{TiO}_{2}$ photocatalysts by FSP and showed improvement over $\mathrm{P} 25 \mathrm{TiO}_{2}$ in the photocatalytic mineralisation of sucrose [47]. As we later found out, the FSP-madeTiO $\mathrm{T}_{2}$ consistently outperformed P25 (despite both having similar anatase:rutile ratio, the two most common polymorphic phases of $\mathrm{TiO}_{2}$ ) in the degradation of saccharides, that is, sucrose, glucose and fructose [48]. The trapping of photoelectrons at the surface defect sites of $\mathrm{FSP} \mathrm{TiO}_{2}$, as confirmed by electroparamagnetic resonance (Figure 1e), was thought to be beneficial in the direct charge transfer to the saccharides that enhanced degradation. However, when the same $\mathrm{FSP} \mathrm{TiO}_{2}$ was assessed for the photocatalytic mineralisation of phenol and methanol, it showed inferior activity compared to P25 [48]. This was traced to the fact that these compounds are both hydroxyl radical scavengers, which the FSP $\mathrm{TiO}_{2}$ showed approximately $10 \%$ less efficiency in generating free hydroxyl radicals compared to P25 [48]. Such example where a photocatalyst shows high efficiency in the degradation of a single class compound but less efficiency in another is not unusual. In fact, it is a general phenomenon since every photocatalyst has its own distinct physicochemical characteristic that favours certain degradation pathways. Given the infinitely large number of organic substrates and their degradation pathways, it should be stressed here that there is not one photocatalyst that fits all.

While the electron-trapping surface defects may appear to favour the degradation of saccharides, the high defects content in conventionally-prepared FSP photocatalysts slow down the bulk electron diffusion since the photoelectrons are shallowly and deeply trapped at these sites [49]. The limitation can be overcome by synthesising the $\mathrm{TiO}_{2}$ in a quartz tube-enclosed FSP (Figure 1g) [50]. By doing so, the free entrainment of ambient air can be prevented, and hence the flame residence time at high temperature regions can be prolonged for defects healing. As a result, the capacitance, or the amount of charge trapping defects, was reduced by an order of magnitude (Figure 1h), but at the expense of larger crystallite size since the longer residence time at high temperature zone resulted in severe sintering of the aerosols [49,51]. Typically, the product particle size is increased by a few-fold compared to the conventional open, non-enclosed flame (Figures 1a-d).

In $\mathrm{TiO}_{2}$ photocatalysis, the hypothesis of synergetic photocatalytic effect surrounding mixed $\mathrm{TiO}_{2}$ anatase-rutile polymorphs is a subject of fundamental interest. Optimal mixture of anatase and rutile exists where it is photocatalytically more active than their respective pure states [52,53]. This prompted us to design $\mathrm{TiO}_{2}$ photocatalysts with controllable anatase-rutile content by FSP. By regulating the ambient oxygen partial pressures of the aerosol flame within the quartz tube enclosure, it is possible to tune from almost pure anatase to rutile by decreasing the combustion oxygen partial pressures [50]. Perhaps quite uniquely compared to other approaches of $\mathrm{TiO}_{2}$ polymorphic engineering, the enclosed flame synthesis approach resulted in similar crystallite sizes independent of the polymorph content. This could not be easily achieved by conventional thermal annealing of anatase $\mathrm{TiO}_{2}$, where the rutile content increases as a function of temperature above $400{ }^{\circ} \mathrm{C}$ with corresponding particles sintering [54]. By synthesising an entire range of anatase-rutile concentration independent of size by enclosed FSP, we reported a wide range of anatase-rutile concentration window (13\%-79\% anatase, the remaining as rutile) for which the synergetic hydrogen evolution can be observed [45]. This was attributed to the favourable charge separation across anatase-rutile interface, but such an effect was only possible when the two phases exist in intimate interparticle contact. Physical mixture 
by grinding of the equivalent amount of preformed anatase and rutile could not reproduce the synergetic effect since the two phases are only contacted at inter-aggregate level [45].

Figure 1. Transmission electron micrograph of $\mathrm{TiO}_{2}$ nanoparticles prepared in an (a) open ambient FSP; and (d) quartz tube-enclosed FSP, adapted with permission from [45]; Schematic illustration of (b) small open flame-synthesised photocatalyst with charge trapping defects; and (c) large enclosed flame-synthesised photocatalyst with minimum charge trapping defects; (e) Compared to commercial P25, as-prepared open flame FSP $\mathrm{TiO}_{2}$ particles show the presence of more reductive sites, i.e., $\mathrm{Ti}^{4+}+\mathrm{e}^{-} \rightarrow \mathrm{Ti}^{3+}$, as measured by electron paramagnetic resonance (EPR) under UV exposure at $77 \mathrm{~K}$; (f) Schematic of the process of aerosol nanoparticles formation by the gas-to-particle route (not to scale) and a photograph of the actual aerosol flame; (g) Schematic diagram of the quartz-tube enclosed FSP preventing the entrainment of ambient air thereby prolonging the high temperature region in the aerosol flame, adapted with permission from [50]; (h) Capacitance measurements of $\mathrm{FSP} \mathrm{TiO}_{2}$ synthesised in an open flame shows more charge traps (hence higher capacitance), compared to those synthesised in a quartz tube-enclosed flame, adapted with permission from [49].

Ambient exposed aerosol flame synthesis (Open flame)
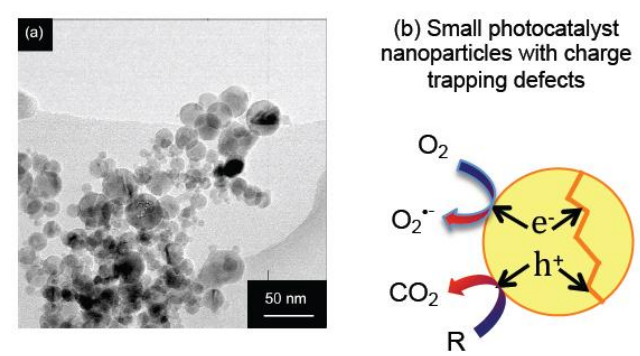

Quartz tube-enclosed aerosol flame synthesis (Enclosed flame)
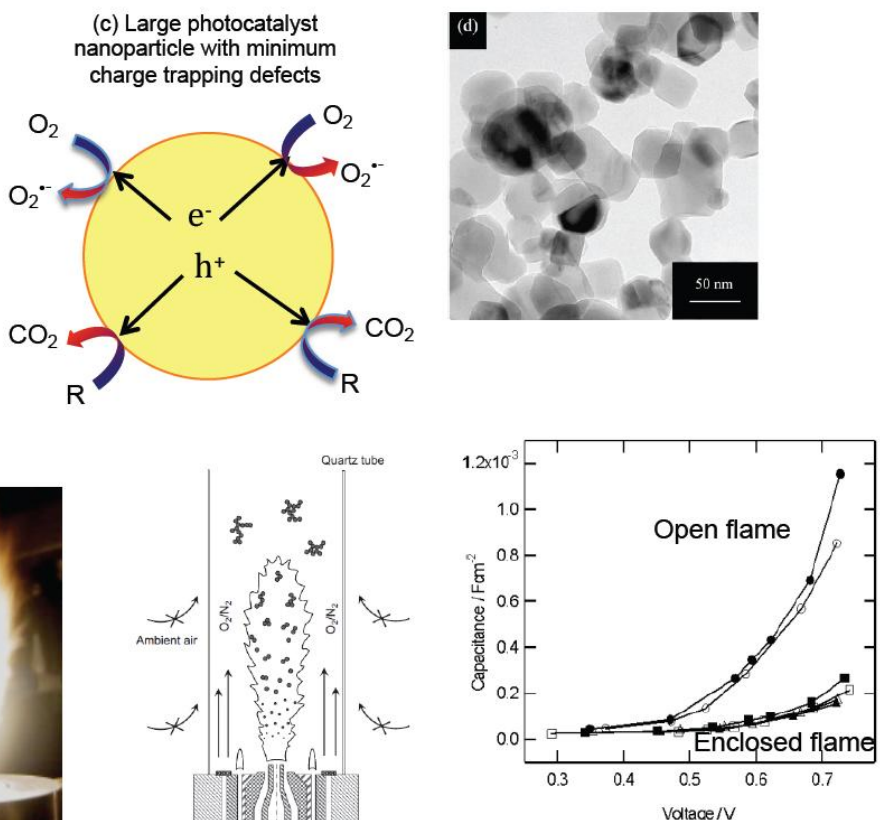

(h) Open flame particles showing much higher capacitance as a result of higher density of photoelectrons trapping at defect sites

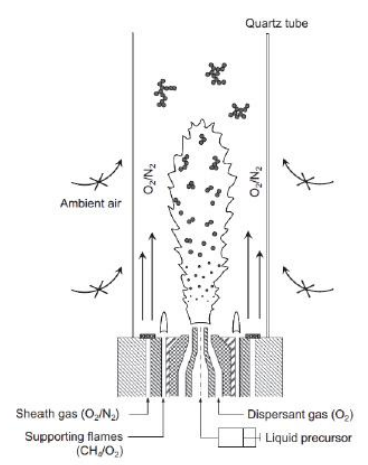
entrainment of ambient air and at the same time allows control of combustion environment (g) Quartz tube-enclosure prevents (e) Electron paramagnetic resonance showing trapping at $\mathrm{Ti}^{3+}$ sites (f) Sequential aerosol particles formation stages during FSP (scheme not to scale) 
Extending the studies further, we investigated the polymorphic effect of $\mathrm{FSP} \mathrm{TiO}_{2}$ nanocrystals on the photocatalytic degradation of different organic compounds. As shown in Figure 2b, a synergetic photocatalytic mineralisation of sucrose can be observed in the range of $37 \%-70 \%$ anatase. In this instance, the enhanced charge separation at the anatase-rutile interface was thought to be beneficial in direct interfacial charge transfer to sucrose, as consistent with earlier discussion on the mineralisation of saccharides by FSP $\mathrm{TiO}_{2}$. For other classes of compounds, namely oxalic acid (Figure 2a) and phenol (Figure 2c), the mineralisation rates appear to be favoured by high anatase content. Many polymorphic studies also reported favourable activity over anatase $\mathrm{TiO}_{2}$, tracing it to the higher yield of hydroxyl radicals [54]. These results reiterate our earlier message that the efficacy of a photocatalyst is highly specific to the degradation mechanistic pathways of the organic substrates.

Figure 2. Half-life mineralisation rates of (a) oxalic acid; (b) sucrose and (c) phenol over $\mathrm{TiO}_{2}$ nanoparticles of different anatase content (Rutile (mol \%) $=100 \%$ minus Anatase) prepared in a quartz tube-enclosed FSP. Catalyst loadings $0.2 \mathrm{~g} / \mathrm{L}$; Initial carbon loading $2000 \mu \mathrm{g}$; Initial pH 3.0; Light source: 16 W Blacklight blue fluorescence. Data courtesy of Rose Amal and coworkers [55].
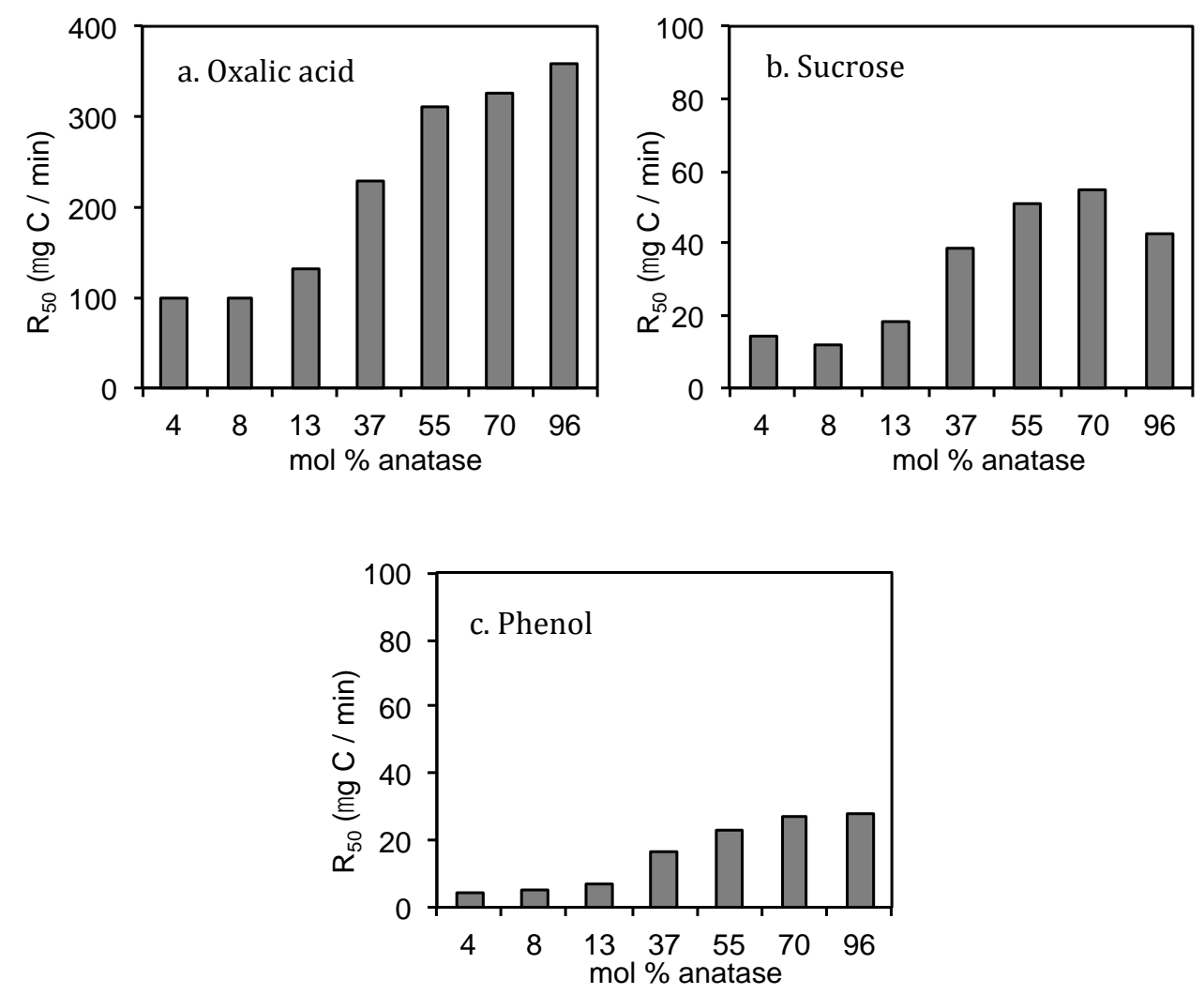

Moving away from $\mathrm{TiO}_{2}, \mathrm{ZnO}$ is one of the leading alternative photocatalysts, which has similar conduction and valence band edges as $\mathrm{TiO}_{2}$. Its syntheses by $\mathrm{FSP}$ have been relatively wellexplored [26,56]. Height et al. [57] showed comparable reaction kinetics between FSP-made ZnO and $\mathrm{P} 25 \mathrm{TiO}_{2}$ in the photocatalytic degradation of methylene blue dye. However, the biggest concern of $\mathrm{ZnO}$ is its chemical stability, i.e., materials corrosion, both in the dark as well as under photoexcitation. Under intrinsic excitation, the photo-generated holes weaken the $\mathrm{Zn}-\mathrm{O}$ bonds, resulting in soluble $\mathrm{Zn}^{2+}$ ions and $\mathrm{O}_{2}$ [58]. For this reason, it is essential to monitor soluble $\mathrm{Zn}$ 
concentration during photocatalysis, especially in the presence of complexing agents which may further aggravate the effects of dissolution $[59,60]$.

$\mathrm{WO}_{3}$ is an interesting visible light-driven, mid-bandgap photocatalyst, for which the conduction band edge $(+0.5 \mathrm{~V}$ vs. NHE) is more positive than the redox of superoxide radical formation: $E\left(\mathrm{O}_{2} / \mathrm{O}_{2}{ }^{-}\right)=-0.33 \mathrm{~V} v s$. NHE [61]. In other words, the standard practice of air or oxygen purging during photocatalytic assessment will be ineffective for $\mathrm{WO}_{3}$, at least when used without co-catalyst. To overcome this, co-catalysts such as $\mathrm{Pt}$ deposits are often introduced to promote alternative multiple electron reduction of oxygen: $\mathrm{O}_{2}+2 \mathrm{H}^{+}+2 \mathrm{e}^{-} \rightarrow \mathrm{H}_{2} \mathrm{O}_{2}\left(+0.695 \mathrm{~V}\right.$ vs. NHE), and $\mathrm{O}_{2}+4 \mathrm{H}^{+}+4 \mathrm{e}^{-} \rightarrow 2 \mathrm{H}_{2} \mathrm{O}$ $(+1.23 \mathrm{~V}$ vs. NHE). In terms of FSP synthesis, a suitable commercial tungsten precursor with high enough concentration for high throughput synthesis of pure $\mathrm{WO}_{3}$ has been a major hurdle in the past, as only 10 vol \% tungsten 2-ethylhexanoate in hexane is available commercially. In recent years, the high concentration formulation of tungsten benzoate through the spontaneous reaction of tungsten hexachloride with benzoic acid has substituted for such needs [62]. Despite yielding highly crystalline $\mathrm{WO}_{3}$ nanocrystals from FSP using this precursor, no published data on its photocatalytic characteristics is yet available, be it in its pristine form or that loaded with co-catalysts. In any case, it is essential to compare both states to obtain fundamentals information on its photo-physicochemical properties as well as its ability to catalyse multiple electrons reduction of $\mathrm{O}_{2}$ when decorated with co-catalysts.

As general good practice, care should be taken when assessing the efficiencies of photocatalysts with regard to the choice of organic substrates and the light source. We take the opportunity to echo the message by Professor Bunsho Ohtani [63,64], which has been wellreceived within the photocatalysis community, that the effects of organics (and more prominently dyes) degradation by photosensitisation-degradation and photocatalytic oxidation should be distinguished. In the former, dyes absorb suitable photons resulting in the excitation of ground state electrons from HOMO to LUMO. The LUMO electrons then inject into the conduction band of the photocatalyst. In the case if the electrons are not regenerated at HOMO, the dye will degrade, even without photogenerated charges from the photocatalyst. In other words, the degradation of dyes cannot fully reflect the photocatalytic efficiencies of the photocatalysts.

Figure 3 shows the optical absorbance of various FSP-made wide and mid-bandgap photocatalysts, as well as some of the more common organic substrates. Wide absorbance organic dyes such as methylene blue and rhodamine B are difficult to avoid photosensitisation. To complicate things, it is not uncommon to observe the shifting of the absorbance profile during the course of dyes degradation. Non-dye substrates are in general less problematic as they rarely have overlap absorbance with the assessed photocatalysts. As precautions, even when assessing the photocatalytic degradation of aromatic compounds (absorbance $<300 \mathrm{~nm}$ ), cut off filters below their absorbance can be coupled to the light source to avoid photosensitisation. 
Figure 3. (a) Normalised Kubelka-Munk absorbance of various photocatalysts prepared by FSP as measured in diffuse-reflectance mode in an integrating sphere; and (b) absorbance of a range of commonly employed substrates $(0.1 \mathrm{mM})$ used in the assessment of photocatalysts.

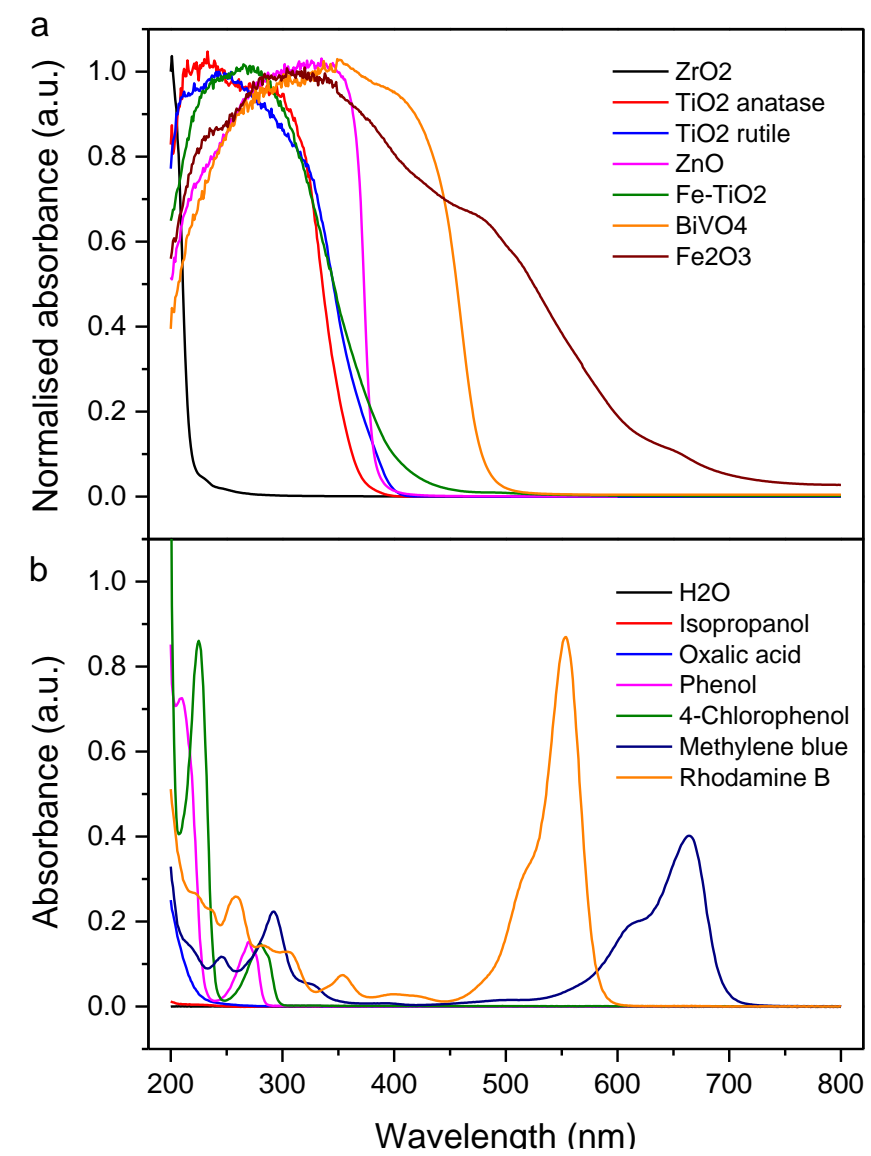

\section{In situ Flame-doping of Photocatalysts-A Small Addition Makes Big Changes}

Doping of metal oxide photocatalysts can be conveniently carried out in FSP by co-dissolving foreign metal precursors in the overall precursor formulation. Because of the well-controlled stoichiometry of both the parent metal elements and that of dopants, this allows precise engineering of the dopant concentrations during synthesis, almost unparalleled by other doping techniques [33]. However, the challenge has been to achieve the desirable specific physicochemical states of the dopants. They include the control of substitutional or interstitial doping, whether the dopants are surface concentrated or distributed homogeneously as solid solutions, or whether the dopants maintain the desirable oxidation states and coordination number, etc. More specific questions pertaining to photocatalysts design include, how can one obtain a surface-enriched doping of $\mathrm{Rh}^{3+}$ in $\mathrm{SrTiO}_{3}$, instead of being homogeneously distributed? Can we obtain more $\mathrm{V}^{4+}$ doping instead of $\mathrm{V}^{5+}$ on $\mathrm{TiO}_{2}$ surface, or can we obtain exclusive interstitial instead of substitutional $\mathrm{Ti}^{4+}$ doping in $\mathrm{Fe}_{2} \mathrm{O}_{3}$ ? Despite the importance of these outcomes that are in turn vital to the successful design of the doped photocatalysts, many of these challenges in FSP synthesis remain underexplored. 
In search of visible light-activated photocatalysts, we reported the FSP synthesis of $\mathrm{Fe}^{3+}$-doped $\mathrm{TiO}_{2}$ photocatalyst that was active in the mineralisation of oxalic acid [65]. Doping $\mathrm{Fe}^{3+}$ in $\mathrm{TiO}_{2}$ created sub-bandgap energy levels from which electrons can exist and be photoexcited to conduction band with lower energy photons, i.e., visible light (Figure 4a) [66]. Because of the extremely high synthesis temperature and rapid quenching of the aerosol flame (from radiation heat loss and air entrainment), homogeneous doping as high as Fe/Ti $=0.05$ can be achieved from FSP synthesis, which is 2.5 times higher than traditionally prepared by wet techniques. For this, we found that Fe-doped $\mathrm{TiO}_{2}(\mathrm{Fe} / \mathrm{Ti}=0.02)$ exhibited optimal visible light activity. However, the mechanism of oxalic acid mineralisation over Fe-doped $\mathrm{TiO}_{2}$ was not a simple photohole oxidation. Such insight was only obtained when following the stability of the dopant during the course of the reaction. An intriguing homogeneous-heterogeneous reaction actually took place with initial complexation-leaching between surface $\mathrm{Fe}$ (III) and adsorbed oxalic acid to form $\mathrm{Fe}$ (III)-oxalate, which decomposes under visible light [65]. This results in free $\mathrm{Fe}(\mathrm{II})$ that then readsorbs on the $\mathrm{Fe}-\mathrm{TiO}_{2}$ surface, and reoxidized by photoholes to regenerate $\mathrm{Fe}$ (III) [65]. The unique leaching and readsorption allows recovery of all $\mathrm{Fe}$ dopants to be reused effectively.

Figure 4. Tauc plot of pristine and metal-doped $\mathrm{TiO}_{2}$ at various loadings (expressed in atomic percentage with respect to $\mathrm{Ti}$ ) prepared in a one-step FSP. The metal dopants include (a) Fe; (b) Co; (c) Mn and (d) V.
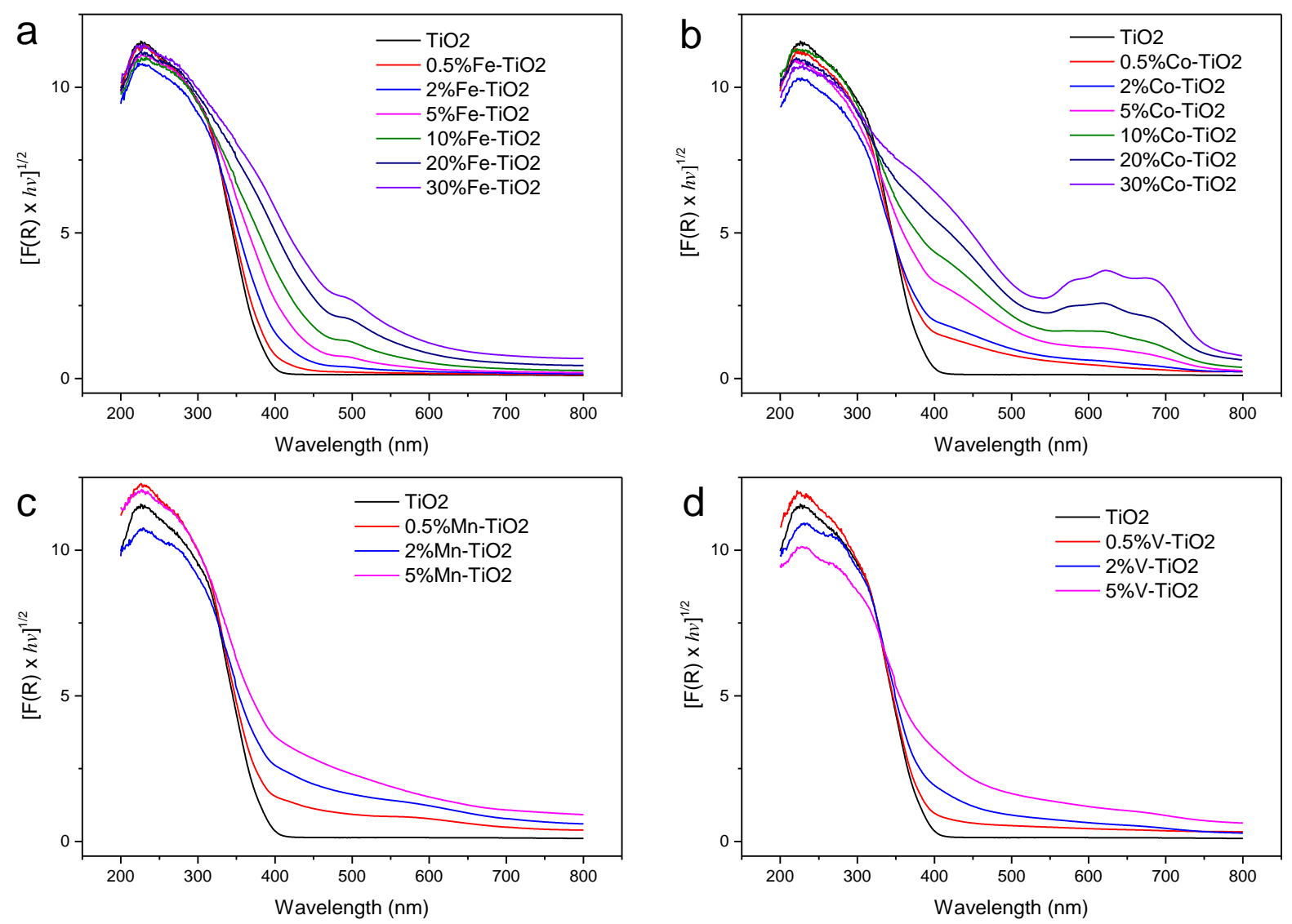
As with any metal-doped photocatalysts, it is essential to investigate the stability of the dopants to gain real insights into its degradation mechanism. One should always assume that dopants are unstable, unless proven otherwise. There are only some isolated cases, such as Fe-doped $\mathrm{ZnO}$ [67], where the dopants actually help increase aqueous stability of the photocatalysts. Here, the stability was thought to originate from the formation of zinc ferrite-like phase [68].

By extension of the one-step FSP synthesis of Fe-doped $\mathrm{TiO}_{2}$, similar attempts were made with $\mathrm{V}$, $\mathrm{Co}$ and $\mathrm{Mn}$ dopants. However, these dopants only exhibit partial (shoulder like) extension of the $\mathrm{TiO}_{2}$ intrinsic absorption edge, which is likely due to inhomogeneity of the metal dopants (Figure 4). Vanadium, for example, tends to concentrate on the $\mathrm{TiO}_{2}$ surface during flame synthesis [69]. Tian et al. [70] reported enhancement in the degradation of methylene blue dye over FSP-made V-doped $\mathrm{TiO}_{2}$ compared to bare $\mathrm{TiO}_{2}$ under both $\mathrm{UV}$ (optimal $0.5 \% \mathrm{~V}-\mathrm{TiO}_{2}$ ) and visible light irradiation (optimal $1 \% \mathrm{~V}-\mathrm{TiO}_{2}$ ). Evidence of $\mathrm{V}^{4+}$ substitutional doping was suggested based on EPR spectroscopy, alongside surface layer $\mathrm{V}^{5+}$ which was otherwise electroparamagnetically invisible [70,71]. In general, phase segregation any dopants ought to occur when the solid-state solubility limit is exceeded. Figure $4 \mathrm{~b}$ shows the segregation of cobalt oxide at $>5$ at $\%$ loading as evident from the 550-750 nm band.

Besides modifying the band structure of the parent oxide photocatalyst, doping has pronounced effects on the hydroxyl group density. By using FSP-made photocatalysts, Jiang et al. [72] showed the increase in photocatalytic oxidation of acetaldehyde with decreasing terminal Ti-OH group achieved by doping. The hydroxyl group density follows the order of Cu-doped $\mathrm{TiO}_{2}>$ FSP $\mathrm{TiO}_{2}>\mathrm{P} 25>$ F-doped $\mathrm{TiO}_{2}$. Unlike aqueous phase photocatalysis, less hydroxyl groups allows more efficient direct charge transfer, which is the dominant mechanism in the gas phase photocatalytic oxidation.

\section{Flame-Made Mixed Metal Oxide Photocatalysts_-Trying out Complexities}

To date, the variety of FSP-synthesised mixed metal oxide photocatalysts has been limited despite its huge potential for the discovery of new materials through bandgap engineering, a strategy widely adopted in the design of water splitting photocatalysts [73]. By comparisons, the FSP synthesis of mixed metal oxides in other applications has made more significant progress in terms of the number of successful high-performance materials synthesised: For examples, thermal catalysis $\left(\mathrm{Ce}_{x} \mathrm{Zr}_{1-x} \mathrm{O}_{2}\right.$ three-way catalysts [40], $\mathrm{CuO}-\mathrm{CeO}_{2} \mathrm{PrO}_{x}$ [23,24] and $d e \mathrm{NO}_{x}$ catalysts [25], $\mathrm{V}_{2} \mathrm{O}_{5} / \mathrm{TiO}_{2}$ oxidation catalyst) [69], $\mathrm{Li}$-ion batteries $\left(\mathrm{LiMn}_{2} \mathrm{O}_{4}, \mathrm{Li}_{4} \mathrm{Ti}_{5} \mathrm{O}_{12}, \mathrm{LiFe}_{5} \mathrm{PO}_{8}\right)$ [37,74], gas sensors $\left(\mathrm{In}_{4} \mathrm{Sn}_{3} \mathrm{O}_{12}\right)$ [75] and biomaterials (hydroxyapatite [76], dental fillers [77], bioglass [78]). Like the general FSP syntheses of photocatalyst nanoparticles, the challenge lies in the synthesis of highly crystallined and defects-free nanoparticles, except that the challenge is drastically augmented with increase in the number of metal elements. As such, only a couple of cases of decent mixed oxide photocatalysts have been reported thus far.

$\mathrm{BiVO}_{4}$ is an active visible light-driven photocatalyst with highly oxidising valence band edge. Strobel et al. [79] reported the FSP synthesis of this vivid yellow pigment with a bandgap of $\sim 2.5 \mathrm{eV}$. The synthesis of $\mathrm{BiVO}_{4}$ by FSP is an interesting one in that the $\mathrm{BiVO}_{4}$ aerosol leaving the flame is actually in an amorphous state. However, the later exposure to high temperature heat directly above the flame during filter-collection $\left(T>310{ }^{\circ} \mathrm{C}\right)$ resulted in the crystallisation of $\mathrm{BiVO}_{4}$, i.e., on the filter [79]. In as-collected form, the $\mathrm{BiVO}_{4}$ shows decent activity in the photobleaching of methylene 
blue [80]. By controlling precisely the filter exposure temperature, one is able to tune the polymorphic phase of the $\mathrm{BiVO}_{4}$ crystal, which in turn reflects its photocatalytic activity. At relatively low temperature but above crystallisation temperature, photoactive scheelite-monoclinic phase can be obtained up to $430{ }^{\circ} \mathrm{C}$, above which the less active scheelite-tetragonal phase will dominate [43]. To further enhance the photocatalytic activity of the $\mathrm{BiVO}_{4}$, the large presence of oxygen vacancies and other defects ought to be overcome. Post-treatment with aqueous acid-dissolved bismuth nitrate and vanadia was found to "heal" these recombination centres and significantly improved the photocatalytic oxygen evolution under visible light by 5 -fold [43].

Akurati et al. [81] introduced the $\mathrm{WO}_{3} / \mathrm{TiO}_{2}$ composite photocatalyst to tune the surface Brønsted and Lewis acidity of the $\mathrm{TiO}_{2}$. This is a common strategy in thermal catalysis, which when applied to photocatalysis, has the additional role of improved charge separation across the heterojunctions of $\mathrm{TiO}_{2}$ and $\mathrm{WO}_{3}$, as shown for the enhanced degradation of methylene blue [81]. In this regards, the transfer of accumulated photoelectrons on $\mathrm{W}^{5+}$ would require the deposition of $\mathrm{Pt}$ or $\mathrm{Cu}^{2+}$ co-catalyst for the multiple electron reduction of oxygen (as mentioned earlier) [61].

As we see it, there are two major hurdles that need to be overcome to pave the way for more successful synthesis of mixed oxide photocatalysts by FSP: (i) The first being the quality of the resultant mixed oxide crystals. It appears that for composite photocatalysts, especially those of complex oxides, much longer residence time at high flame temperature is often required to achieve adequate crystallisation and minimising of charge trap defects. This will however compromise on the specific surface area (or crystallite size). Although the quartz-tube enclosed can prolong the required residence time, we found in the (perhaps isolated) case of $\mathrm{BiVO}_{4}$ where the accompanied high temperature flame resulted in the unfavourable high temperature zircon phase and sublimation of $\mathrm{Bi}$, resulting in even more defects; (ii) The second criterion is the limitation of precursors. Although we did mention earlier that one of the main advantages of FSP lies in its innate ability to utilise liquid precursors, more exotic metallorganic precursors such as those containing $\mathrm{Ga}, \mathrm{Ta}, \mathrm{Sr}, \mathrm{Sb}, \mathrm{La}$ and $\mathrm{Pr}$, which are commonly used elements in the design of mixed oxide photocatalysts, are either still unavailable or too expensive. In this respect, the upgrading of these metal precursors from low cost metal nitrates, acetates or even oxides to suitable metallorganics remains a major bottleneck.

\section{Flame Deposition of Noble Metals on Oxide Photocatalysts}

The deposition of noble metals is a classical technique for enhancing charge separation and the photocatalytic reaction rates. At the metal-semiconductor interface, Schottky barrier is formed due to the difference between Fermi energy level and the conduction band edge of the semiconductor photocatalyst. This prevents trapped photoelectrons from back flowing to the photocatalyst conduction band, and hence better charge separation can be achieved. The noble metal/photocatalyst structures explored by FSP include $\mathrm{Pt} / \mathrm{TiO}_{2}$ [47], $\mathrm{Ag} / \mathrm{TiO}_{2}$ [27], $\mathrm{Au} / \mathrm{TiO}_{2}$ [82] and $\mathrm{Ag} / \mathrm{ZnO}$ [57]. The segregation of the noble metals as nanosize deposits during FSP relies on the fact that (i) the noble metal has relatively low boiling/sublimation point of the metal compared to oxide photocatalyst, so that the former precipitates at a later stage in the flame after the precipitation of the oxide photocatalyst support, and/or (ii) low solubility of the two phases which otherwise enhances bulk doping rather than surface deposition. Recalling the effects of metal precursors that determine if the FSP-made particles 
are formed by the gas-to-particle or droplet-to-particle route, the same principle applies to the deposition of noble metals. Typically, the use of noble metal acetylacetonates and carboxylates ensure the formation of homogeneous deposits (of 2-5 nm) [27] through the gas-to-particle precipitation, while noble metal nitrates result in inhomogeneous deposits $(2-50 \mathrm{~nm})$ by the droplet-to-particle route [57].

All the photocatalysis cases reported so far on the deposition of noble metal by FSP has resulted in the enhancement of photocatalytic activities (that is at optimal concentration), compared to the corresponding bare oxides. Typically, an optimum concentration of exists, beyond which the metal deposits become recombination centres and at even higher concentration may result in the shielding of light absorption. This is true irrespective of the organic test substrates, be it saccharides [47], carboxylic acids, alcohols, aromatics [83] or dyes [57]. Perhaps quite differently from the typical photocatalytic assessments, Chiarello et al. [84,85] demonstrated the photocatalytic reforming of gaseous methanol over FSP-made $\mathrm{Pt} / \mathrm{TiO}_{2}$ to form carbon monoxide and hydrogen. The FSP-prepared $\mathrm{Pt} / \mathrm{TiO}_{2}$ showed drastically higher photocatalytic activity than that prepared by wet technique as a result of higher noble metal dispersion.

Strictly speaking, the oxidation states of the as-prepared metal deposits are in oxide forms, at least shown for $\mathrm{Ag}_{2} \mathrm{O}$ [27] and PtO [47,83] on $\mathrm{TiO}_{2}$. Because these noble metals are electrons traps, they can be easily reduced under excitation of the photocatalyst support. An intricate phenomenon that has often been overlooked is the dynamic of oxidation states of the noble metal deposits, which besides the Schottky electron trapping, is deeply correlated with the mechanistic pathway of the photocatalytic reactions. For instance, the photocatalytic oxidation of formic acid results in the formation of highly reducing COO radical [84], which readily reduces $\mathrm{PtO}$ to metallic $\mathrm{Pt}$ [83]. The photocatalytic degradation of aromatic-containing compounds involves a null redox cycle between hydroquinone and benzoquinone [4], where the reduction of benzoquinone to hydroquinone results in the oxidation of $\mathrm{Pt}$ deposits and vice versa for the cyclic reoxidation to benzoquinone. As such the initial Pt(II) state may, at the end of reaction, exist in mixed oxidation states $\operatorname{Pt}(0$, II and IV), the composition of which reflects the overall reaction path [83]. Additionally, the co-catalytic effects of noble metal deposits may be beneficial and contributing to the overall photocatalytic reaction, and hence shall not be completely ignored.

Since metal deposits can be reduced to metallic state upon photoexcitation of the photocatalysts, this gives rise to the surface plasmon resonance, as evident in the visible wavelengths for metals such as $\mathrm{Ag}$ and $\mathrm{Au}$. As shown in Figure 5, $\mathrm{Ag}(\mathrm{I})$ and $\mathrm{Ag}(0)$ can inter-switch reversibly by irradiating $\mathrm{Ag} / \mathrm{TiO}_{2}$ photocatalyst with $\mathrm{UV}(\mathrm{Ag}(0)$ to $\mathrm{Ag}(\mathrm{I}))$ and visible light $(\mathrm{Ag}(\mathrm{I})$ to $\mathrm{Ag}(0))$ [27]. Perhaps interesting to mention, the surface plasmon absorption by metal deposits can generate a localised electric field that may enhance charge separation on the photocatalyst and the resultant photocatalytic activities [86]. However, it is to date difficult to decouple, at least from the photocatalytic asessments alone, the combination of effects from Schottky barrier, co-catalyst and surface plasmon resonance. 
Figure 5. Transmission electron micrographs of FSP-made $\mathrm{Ag} / \mathrm{TiO}_{2}$ samples after UV and visible light irradiation. Under UV irradiation, $\mathrm{Ag}(\mathrm{I})$ oxide deposits are photoreduced and result in the increase in surface plasmon resonance as characteristics of metallic $\mathrm{Ag}$. Irradiation by visible light resulted in the injection of excited electrons from metallic $\mathrm{Ag}$ to the conduction band of $\mathrm{TiO}_{2}$, and in the process oxidising it back to $\mathrm{Ag}(\mathrm{I})$ oxide. This resulted in the loss of surface plasmon resonance effects. Adapted with permission from [26].
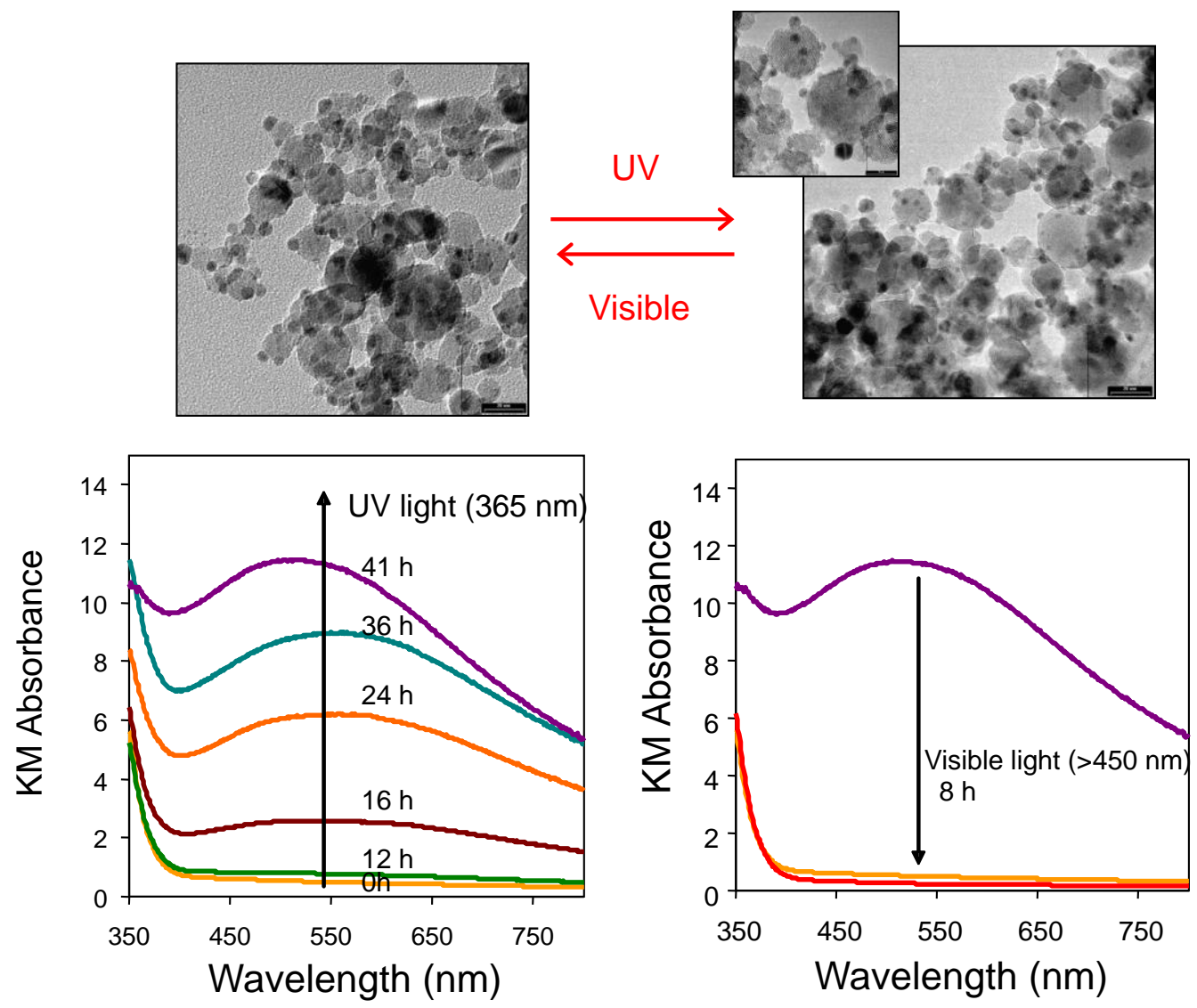

\section{Concluding Remarks}

The integration of FSP as a mainstream technique for photocatalysts synthesis is still in its dawn. Whilst some design strategies established for the synthesis of thermal catalysts may be transferable to the designing of photocatalysts, the priorities of these design criteria can be quite different. Experience gained from the synthesis of simple metal oxide photocatalysts, has identified perhaps the most fundamental challenge that ought to be overcome: photocharge trap defects arising from the extremely short flame residence time. Overcoming this very challenge is even more daunting for mixed oxide photocatalysts, but one that holds unprecedented potential for novel photocatalysts design. The same challenge applies to the general FSP synthesis of other functional materials involving charge transport (solar cells), electrons spin (superconductor, magnetic and spintronic applications), and energy transfer (phosphors), for which efficiencies are highly dependent on the quality of the nanocrystals. An area that FSP may prevail over the more established wet synthesis of photocatalysts, in addition to the readily scalable process to industrial mass, is the ability to yield metastable photocatalysts. These metastable materials are obtained in part because of the short flame residence time at extreme conditions. If photocatalysts can be designed and at the same time overcoming the inherent charge trap 
defects and recombination centres, this can potentially result in a new class of efficient photocatalysts that is unique to flame synthesis.

\section{Acknowledgements}

The author acknowledges Wenny Irawaty, Mandalena Hermawan and Rose Amal of the Particles and Catalysis Research Group, The University of New South Wales (UNSW) for the photocatalytic assessment data of polymorphic $\mathrm{TiO}_{2}$, and Jimmy C. Yu of the Chinese University of Hong Kong (CUHK) on the EPR measurements. The work is made possible by the Research Grant Council (RGC) of Hong Kong through the General Research Fund (103311) and Early Career Scheme Grant (104812).

\section{Conflict of Interest}

The authors declare no conflict of interest.

\section{References}

1. Pratsinis, S.E. Flame Aerosol Synthesis of Ceramic Powders. Prog. Energy Combust. Sci. 1998, 24, 197-219.

2. Chemical Economics Handbook; SRI International: Merlo Park, CA, USA, 2001.

3. Ollis, D.F.; Al-Ekabi, H. Photocatalytic Purification and Treatment of Water and Air; Elsevier Science Ltd.: Amsterdam, the Netherlands, 1993.

4. Teoh, W.Y.; Scott, J.A.; Amal, R. Progress in Heterogeneous Photocatalysis: From Classical Radical Chemistry to Engineering Nanomaterials and Solar Reactors. J. Phys. Chem. Lett. 2012, 3, 629-639.

5. Kraeutler, B.; Bard, A.J. Heterogeneous Photocatalytic Synthesis of Methane from Acetic Acid-New Kolbe Reaction Pathway. J. Am. Chem. Soc. 1978, 100, 2239-2240.

6. Abe, T.; Suzuki, E.; Nagoshi, K.; Miyashita, K.; Kaneko, M. Electron Source in Photoinduced Hydrogen Production on Pt-supported $\mathrm{TiO}_{2}$ Particles. J. Phys. Chem. B 1999, 103, 1119-1123.

7. Ito, S.; Chen, P.; Comte, P.; Nazeeruddin, M.K.; Liska, P.; Pechy, P.; Gratzel, M. Fabrication of Screen-Printing Pastes from $\mathrm{TiO}_{2}$ Powders for Dye-Sensitised Solar Cells. Prog. Photovolt. 2007, 15, 603-612.

8. Hurum, D.C.; Agrios, A.G.; Gray, K.A.; Rajh, T.; Thurnauer, M.C. Explaining the Enhanced Photocatalytic Activity of Degussa P25 Mixed-Phase $\mathrm{TiO}_{2}$ Using EPR. J. Phys. Chem. B 2003, 107, 4545-4549.

9. Li, G.; Chen, L.; Graham, M.E.; Gray, K.A. A Comparison of Mixed Phase Titania Photocatalysts Prepared by Physical and Chemical Methods: The Importance of the Solid-Solid Interface. J. Mol. Catal. A Chem. 2007, 275, 30-35.

10. Ohtani, B.; Prieto-Mahaney, O.O.; Lin, D.; Abe, R. What is Degussa (Evonik) P25? Crystalline Composition Analysis, Reconstruction from Isolated Pure Particles and Photocatalytic Activity Test. J. Photochem. Photobiol. A. 2010, 218, 179-182.

11. Sokolowski, M.; Sokolowska, A.; Michalski, A.; Gokieli, B. The "In-Flame-Reaction" Method for $\mathrm{Al}_{2} \mathrm{O}_{3}$ Aerosol Formation. J. Aerosol Sci. 1977, 8, 219-230. 
12. Laine, R.M.; Hinklin, T.; Williams, G.; Rand, S.C. Low-Cost Nanopowders for Phosphor and Laser Applications by Flame Spray Pyrolysis. Mater. Sci. Forum 2000, 343-346, 500-510.

13. Strobel, R.; Pratsinis, S.E. Flame Aerosol Synthesis of Smart Nanostructured Materials. J. Mater. Chem. 2007, 17, 4743-4756.

14. Wegner, K.; Schimmoeller, B.; Thiebaut, B.; Fernandez, C.; Rao, T.N. Pilot Plants for Industrial Nanoparticle Production by Flame Spray Pyrolysis. KONA Powder Part. J. 2011, 29, 251-265.

15. Teoh, W.Y.; Amal, R.; Mädler, L. Flame Spray Pyrolysis: An Enabling Technology for Nanoparticles Design and Fabrication. Nanoscale 2010, 2, 1324-1347.

16. Jossen, R.; Pratsinis, S.E.; Stark, W.J.; Mädler, L. Criteria for Flame-Spray Synthesis of Hollow, Shell-like, or Inhomogeneous Oxides. J. Am. Ceram. Soc. 2005, 88, 1388-1393.

17. Bickmore, C.R.; Waldner, K.F.; Treadwell, D.R.; Laine, R.M. Ultrafine Spinel Powders by Flame Spray Pyrolysis of a Magnesium Aluminum Double Alkoxide. J. Am. Ceram. Soc. 1996, 79, 1419-1423.

18. Mädler, L.; Krumeich, F.; Burtscher, P.; Moszner, N. Visibly Transparent and Radiopaque Inorganic-Organic Composites from Flame-Made Mixed-Oxide Fillers. J. Nanopart. Res. 2006, 8, 323-333.

19. Mädler, L. Liquid-Fed Aerosol Reactors for One-Step Synthesis of Nanostructured Particles. KONA 2004, 22, 107-120.

20. Beaucage, G.; Kammler, H.K.; Mueller, R.; Strobel, R.; Agashe, N.; Pratsinis, S.E.; Narayanan, T. Probing the Dynamics of Nanoparticle Growth in a Flame Using Synchrotron Radiation. Nat. Mater. 2004, 3, 370-373.

21. Jossen, R. Controlled synhesis of mixed oxide nanoparticles by flame spray pyrolysis. Ph.D. Dissertation. Swiss Federal Institute of Technology (ETH), Zurich, Switzerland, 2005.

22. Schulz, H.; Stark, W.J.; Maciejewski, M.; Pratsinis, S.E.; Baiker, A. Flame-Made Nanocrystalline Ceria/Zirconia Doped with Alumina or Silica: Structural Properties and Enhanced Oxygen Exchange Capacity. J. Mater. Chem. 2003, 13, 2979-2984.

23. Kydd, R.; Teoh, W.Y.; Wong, K.; Wang, Y.; Scott, J.; Yu, A.B.; Zou, J.; Amal, R. Flame-Synthesized Ceria-Supported Copper Dimers for Preferential Oxidation of CO. Adv. Funct. Mater. 2009, 19, 369-377.

24. Kydd, R.; Ferri, D.; Hug, P.; Scott, J.; Teoh, W.Y.; Amal, R. Temperature-Induced Evolution of Reaction Sites and Mechanisms During Preferential Oxidation of CO. J. Catal. 2011, 277, 64-71.

25. Zhang, R.; Teoh, W.Y.; Amal, R.; Chen, B.; Kaliaguine, S. Catalytic Reduction of NO by CO over $\mathrm{Cu} / \mathrm{Ce}_{x} \mathrm{Zr}_{1-x} \mathrm{O}_{2}$ prepared by flame synthesis. J. Catal. 2010, 272, 210-219.

26. Height, M.J.; Mädler, L.; Pratsinis, S.E.; Krumeich, F. Nanorods of ZnO Made by Flame Spray Pyrolysis. Chem. Mater. 2006, 18, 572-578.

27. Gunawan, C.; Teoh, W.Y.; Marquis, C.P.; Lifia, J.; Amal, R. Reversible Antimicrobial Photoswitching in Nanosilver. Small 2009, 5, 341-344.

28. Strobel, R.; Krumeich, F.; Stark, W.J.; Pratsinis, S.E.; Baiker, A. Flame Spray Synthesis of $\mathrm{Pd} / \mathrm{Al}_{2} \mathrm{O}_{3}$ Catalysts and Their Behavior in Enantioselective Hydrogenation. J. Catal. 2004, 222, 307-314.

29. Hotz, N.; Stutz, M.J.; Loher, S.; Stark, W.J.; Poulikakos, D. Syngas production from butane using a flame-made $\mathrm{Rh} / \mathrm{Ce}_{0.5} \mathrm{Zr}_{0.5} \mathrm{O}_{2}$ catalyst. Appl. Catal. B 2007, 73, 336-344. 
30. Minnermann, M.; Pokhrel, S.; Thiel, K.; Birkenstock, J.; Laurus, T.; Zargham, A.; Flege, J.-I.; Zielasek, V.; Piskorska-Hommel, E.; Falta, J.; et al. Role of Palladium in Iron Based Fischer-Tropsch Catalysts Prepared by Flame Spray Pyrolysis. J. Phys. Chem. C 2011, 115, 1302-1310.

31. Tani, T.; Mädler, L.; Pratsinis, S.E. Synthesis of Zinc Oxide/Silica Composite Nanoparticles by Flame Spray Pyrolysis. J. Mater. Sci. 2002, 37, 4627-4632.

32. Kim, M.; Laine, R.M. One-Step Synthesis of Core-Shell $\left(\mathrm{Ce}_{0.7} \mathrm{Zr}_{0.3} \mathrm{O}_{2}\right)_{x}\left(\mathrm{Al}_{2} \mathrm{O}_{3}\right)_{1-x}$ $\left[\left(\mathrm{Ce}_{0.7} \mathrm{Zr}_{0.3} \mathrm{O}_{2}\right) @ \mathrm{Al}_{2} \mathrm{O}_{3}\right]$ Nanopowders via Liquid-Feed Flame Spray Pyrolysis (LF-FSP) J. Am. Chem. Soc. 2009, 131, 9220-9229.

33. Li, D.; Teoh, W.Y.; Selomulya, C.; Woodward, R.C.; Amal, R.; Rosche, B. Flame-Sprayed Superparamagnetic Bare and Silica-Coated Maghemite Nanoparticles: Synthesis, Characterization, and Protein Adsorption-Desorption. Chem. Mater. 2006, 18, 6403-6413.

34. Li, D.; Teoh, W.Y.; Woodward, R.C.; Cashion, J.D.; Selomulya, C.; Amal, R. Evolution of Morphology and Magnetic Properties in Silica/Maghemite Nanocomposites. J. Phys. Chem. C 2009, 113, 12040-12047.

35. Feng, X.; Sayle, D.C.; Wang, Z.L.; Paras, M.S.; Santora, B.; Sutorik, A.C.; Sayle, T.X.T.; Yang, Y.; Ding, Y.; Wang, X.; et al. Converting Ceria Polyhedral Nanoparticles into Single-Crystal Nanospheres. Science 2006, 312, 1504-1508.

36. Ernst, F.O.; Buchel, R.; Strobel, R.; Pratsinis, S.E. One-Step Flame-Synthesis of Carbon-Embedded and -Supported Platinum Clusters. Chem. Mater. 2008, 20, 2117-2123.

37. Ernst, F.O.; Kammler, H.K.; Roessler, A.; Pratsinis, S.E.; Stark, W.J.; Ufheil, U.; Novak, P. Electrochemically Active Flame-Made Nanosized Spinels: $\mathrm{LiMn}_{2} \mathrm{O}_{4}, \mathrm{Li}_{4} \mathrm{Ti}_{5} \mathrm{O}_{12}$ and $\mathrm{LiFe}_{5} \mathrm{O}_{8}$. Mater. Chem. Phys. 2007, 101, 372-378

38. Chiarello, G.L.; Grunwaldt, J.-D.; Ferri, D.; Krumeich, F.; Oliva, C.; Forni, L.; Baiker, A. Flame Synthesised $\mathrm{LaCoO}_{3}$-Supported Pd: 1. Structure, Thermal Stability and Reducibility. J. Catal. 2007, 252, 127-136.

39. Strobel, R.; Piacentini, M.; Mädler, L.; Maciejewski, M.; Baiker, A.; Pratsinis, S.E. Two-Nozzle Flame Synthesis of $\mathrm{Pt} / \mathrm{Ba} / \mathrm{Al}_{2} \mathrm{O}_{3}$ for $\mathrm{NO}_{x}$ Storage. Chem. Mater. 2006, 18, 2532-2437.

40. Stark, W.J.; Mädler, L.; Maciejewski, M.; Pratsinis, S.E.; Baiker, A. Flame Synthesis of Nanocrystalline Ceria-Zirconia: Effect of Carrier Liquid. Chem. Commun. 2003, doi:10.1039/B211831A.

41. Schimmoeller, B.; Pratsinis, S.E.; Baiker, A. Flame Aerosol Synthesis of Metal Oxide Catalysts with Unprecedented Structural and Catalytic Properties. ChemCatChem 2011, 3, 1234-1256.

42. Emeline, A.V.; Sheremetyeva, N.V.; Khomchenko, N.V.; Kuzmin, G.N.; Ryabchuk, V.K.; Teoh, W.Y.; Amal, R. Spectroscopic Studies of Pristine and Fluorinated Nano- $\mathrm{ZrO}_{2}$ in Photostimulated Heterogeneous Processes. J. Phys. Chem. C 2009, 113, 4566-4574.

43. Kho, Y.K.; Teoh, W.Y.; Iwase, A.; Mädler, L.; Kudo, A.; Amal, R. Flame Preparation of Visible-Light-Responsive $\mathrm{BiVO}_{4}$ Oxygen Evolution Photocatalysts with Subsequent Activation via Aqueous Route. ACS Appl. Mater. Interfaces 2011, 3, 1997-2004.

44. Konta, R.; Ishii, T.; Kato, H.; Kudo, A. Photocatalytic Activities of Noble Metal Ion-doped $\mathrm{SrTiO}_{3}$ under Visible Light Irradiation. J. Phys. Chem. B 2004, 108, 8992-8995. 
45. Kho, Y.K.; Iwase, A.; Teoh, W.Y.; Mädler, L.; Kudo, A.; Amal, R. Photocatalytic $\mathrm{H}_{2}$ Evolution over $\mathrm{TiO}_{2}$ Nanoparticles. The Synergistic Effect of Anatase and Rutile. J. Phys. Chem. C 2010, 114, 2821-2829.

46. Liu, G.; Yu, J.C.; Lu, G.Q.; Cheng, H.M. Crystal Facet Engineering of Semiconductor Photocatalysts: Motivations, Advances and Unique Properties. Chem. Commun. 2011, 47, 6763-6783.

47. Teoh, W.Y.; Mädler, L.; Beydoun, D.; Pratsinis, S.E.; Amal, R. Direct (One-Step) Synthesis of $\mathrm{TiO}_{2}$ and $\mathrm{Pt} / \mathrm{TiO}_{2}$ Nanoparticles for Photocatalytic Mineralisation of Sucrose. Chem. Eng. Sci. 2005, 60, 5852-5861.

48. Teoh, W.Y.; Denny, F.; Amal, R.; Friedmann, D.; Mädler, L.; Pratsinis, S.E. Photocatalytic Mineralisation of Organic Compounds: A Comparison of Flame-Made $\mathrm{TiO}_{2}$ Catalysts. Top. Catal. 2007, 44, 489-497.

49. Tsekuoras, G.; Miyashita, M.; Kho, Y.K.; Teoh, W.Y.; Mozer, A.J.; Amal, R.; Mori, S.; Wallace, G.G. Charge Transport in Dye-Sensitized Solar Cells Based on Flame-Made $\mathrm{TiO}_{2}$ Nanoparticles. IEEE J. Sel. Top. Quantum Electron. 2010, 16, 1641-1648.

50. Kho, Y.K.; Teoh, W.Y.; Mädler, L.; Amal, R. Dopant-Free, Polymorphic Design of $\mathrm{TiO}_{2}$ Nanocrystals by Flame Aerosol Synthesis. Chem. Eng. Sci. 2011, 66, 2409-2416.

51. Li, D.; Teoh, W.Y.; Selomulya, C.; Woodward, R.C.; Munroe, P.; Amal, R. Insight into Microstructural and Magnetic Properties of Flame-Made $\gamma-\mathrm{Fe}_{2} \mathrm{O}_{3}$ Nanoparticles. J. Mater. Chem. 2007, 17, 4876-4884.

52. Ohno, T.; Sarukawa, K.; Matsumura, M. Photocatalytic Activity of Pure Rutile Particles Isolated from $\mathrm{TiO}_{2}$ Powder by Dissolving the Anatase Component Using HF Solution. J. Phys. Chem. B 2001, 105, 2417-2420.

53. Ohno, T.; Tokieda, K.; Higashida, S.; Matsumura, M. Synergism Between Rutile and Anatase $\mathrm{TiO}_{2}$ Particles in Photocatalytic Oxidation of Naphthalene. Appl. Catal. A 2003, 244, 383-391.

54. Tryba, B.; Toyoda, M.; Morawski, A.W.; Nonaka, R.; Inagaki, M. Photocatalytic Activity and OH Radical Formation on $\mathrm{TiO}_{2}$ in the Relation to Crystallinity. Appl. Catal. B 2007, 71, 163-168.

55. Irawaty, W.; Hermawan, M.; Amal, R. The University of New South Wales, Sydney, Australia. Unpublished work, 2013.

56. Tani, T.; Kato, A.; Morisaka, H. Effects of Solvent on Powder Characteristics of Zinc Oxide and Magnesia Prepared by Flame Spray Pyrolysis. J. Ceram. Soc. Jpn. 2005, 113, 255-258.

57. Height, M.J.; Pratsinis, S.E.; Mekasuwandumrong, O.; Praserthdam, P. Ag-ZnO catalysts for UV-photodegradation of methylene blue. Appl. Catal. B 2006, 63, 305-312.

58. Gerischer, H. Electrochemical Behavior of Semiconductors under Illumination. J. Electrochem. Soc. 1966, 113, 1174-1182.

59. Joshi, S.; Ghosh, I.; Pokhrel, S.; Mädler, L.; Nau, W.M. Interactions of Amino Acids and Polypeptides with Metal Oxide Nanoparticles Probed by Fluorescent Indicator Adsorption and Displacement. ACS Nano 2012, 6, 5668-5679.

60. Gunawan, C.; Teoh, W.Y.; Marquis, C.P.; Amal, R. Zinc Oxide Nanoparticles Induce Cell Filamentation in Escherichia coli. Part. Syst. Charact. 2013, 30, 375-380. 
61. Abe, R.; Takami, H.; Murakami, N.; Ohtani, B. Pristine Simple Oxides as Visible Light Driven Photocatalysts: Highly Efficient Decomposition of Organic Compounds over Platinum-Loaded Tungsten Oxide. J. Am. Chem. Soc. 2008, 130, 7780-7781.

62. Pokhrel, S.; Birkenstock, J.; Schowalter, M.; Rosenauer, A.; Mädler, L. Growth of Ultrafine Single Crystalline WO3 Nanoparticles Using Flame Spray Pyrolysis. Cryst. Growth Des. 2010, 10, 632-639.

63. Ohtani, B. Preparing Articles on Photocatalysis-Beyond the Illusions, Misconceptions, and Speculation. Chem. Lett. 2008, 37, 217-229.

64. Yan, X.; Ohno, T.; Nishijima, K.; Abe, R.; Ohtani, B. Is Methylene Blue an Appropriate Substrate for a Photocatalytic Activity Test? A Study with Visible-Light Responsive Titania. Chem. Phys. Lett. 2006, 429, 606-610.

65. Teoh, W.Y.; Amal, R.; Mädler, L.; Pratsinis, S.E. Flame Sprayed Visible Light-Active Fe-TiO for Photomineralisation of Oxalic Acid. Catal. Today 2007, 120, 203-213.

66. Anpo, M.; Takeuchi, M. The Design and Development of Highly Reactive Titanium Oxide Photocatalysts Operating Under Visible Light Irradiation. J. Catal. 2003, 216, 505-516.

67. Li, M.; Pokhrel, S.; Jin, X.; Mädler, L.; Damoiseaux, R.; Hoek, E.M.V. Stability, Bioavailability, and Bacterial Toxicity of $\mathrm{ZnO}$ and Iron-doped $\mathrm{ZnO}$ Nanoparticles in Aquatic Media. Environ. Sci. Technol. 2011, 45, 755-761.

68. McDonald, K.J.; Choi, K.S. Synthesis and Photoelectrochemical Properties of $\mathrm{Fe}_{2} \mathrm{O}_{3} / \mathrm{ZnFe}_{2} \mathrm{O}_{4}$ Composite Photoanodes for Use in Solar Water Oxidation. Chem. Mater. 2011, 23, 4863-4869.

69. Schimmoeller, B.; Schulz, H.; Pratsinis, S.E.; Bareiss, A.; Reitzmann, A.; Kraushaar-Czarnetzki, B. Ceramic Foams Directly-Coated with Flame-Made $\mathrm{V}_{2} \mathrm{O}_{5} / \mathrm{TiO}_{2}$ for Synthesis of Phthalic Anhydride. J. Catal. 2006, 243, 82-92.

70. Tian, B.; Li, C.; Gu, F.; Jiang, H.; Hu, Y.; Zhang, J. Flame Sprayed V-doped $\mathrm{TiO}_{2}$ Nanoparticles with Enhanced Photocatalytic Activity under Visible Light Irradiation. Chem. Eng. J. 2009, 151, 220-227.

71. Martin, S.T.; Morrison, C.L.; Hoffmann, M.R. Photochemical Mechanism of Size-Quantized Vanadium-Doped $\mathrm{TiO}_{2}$ Particles. J. Phys. Chem. 1994, 98, 13695-13704.

72. Jiang, Y.; Scott, J.; Amal, R. Exploring the Relationship between Surface Structure and Photocatalytic Activity of Flame-Made $\mathrm{TiO}_{2}$-Based Catalysts. Appl. Catal. B 2012, 126, 290-297.

73. Kudo, A.; Miseki, Y. Heterogeneous photocatalyst materials for water splitting. Chem. Soc. Rev. 2009, 38, 253-278.

74. Patey, T.J.; Buchel, R.; Ng, S.H.; Krumeich, F.; Pratsinis, S.E.; Novak, P. Flame Co-Synthesis of $\mathrm{LiMn}_{2} \mathrm{O}_{4}$ and Carbon Nanocomposites for High Power Batteries. J. Power Sources 2009, 189, $149-154$.

75. Kammler, J.A.; Pokhrel, S.; Birkenstock, J.; Schowalter, M.; Rosenauer, A.; Barsan, N.; Weimer, U.; Mädler, L. Quenched, Nanocrystalline $\mathrm{In}_{4} \mathrm{Sn}_{3} \mathrm{O}_{12}$ High Temperature Phase for Gas Sensing Applications. Sens. Actuator B 2012, 161, 740-747.

76. Loher, S.; Stark, W.J.; Maciejewski, M.; Baiker, A.; Pratsinis, S.E.; Reichardt, D.; Maspero, F.; Krumeich, F.; Gunther, D. Fluoro-Apatite and Calcium Phosphate Nanoparticles by Flame Synthesis. Chem. Mater. 2005, 17, 36-42. 
77. Schulz, H.; Mädler, L.; Pratsinis, S.E.; Burtscher, P.; Moszner, N. Transparent Nanocomposites of Radiopaque, Flame-Made $\mathrm{Ta}_{2} \mathrm{O}_{5} / \mathrm{SiO}_{2}$ Particles in an Acrylic Matrix. Adv. Funct. Mater. 2005, 15, 830-837.

78. Brunner, T.J.; Grass, R.N.; Stark, W.J. Glass and Bioglass Nanopowders by Flame Synthesis. Chem. Commun. 2006, doi:10.1039/B517501A.

79. Strobel, R.; Metz, H.J.; Pratsinis, S.E. Brilliant Yellow, Transparent Pure, and $\mathrm{SiO}_{2}$-Coated

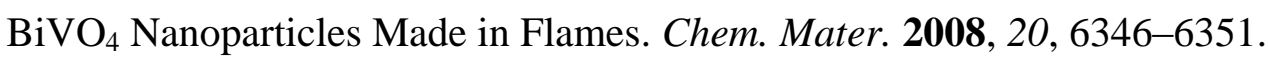

80. Castillo, N.C.; Heel, A.; Graule, T.; Pulgarin, C.Flame-Assisted Synthesis of Nanoscale, Amorphous and Crystalline, Spherical $\mathrm{BiVO}_{4}$ with Visible-Light Photocatalytic Activity. Appl. Catal. B 2010, 95, 335-347.

81. Akurati, K.K.; Vital, A.; Dellemann, J.-P.; Michalow, K.; Graule, T.; Ferri, D.; Baiker, A. Flame-Made $\mathrm{WO}_{3} / \mathrm{TiO}_{2}$ Nanoparticles: Relation between Surface Acidity, Structure and Photocatalytic Activity. Appl. Catal. B 2008, 79, 53-62.

82. Chiarello, G.L.; Selli, E.; Forni, L. Photocatalytic Hydrogen Production over Flame Spray Pyrolysis-Synthesised $\mathrm{TiO}_{2}$ and $\mathrm{Au} / \mathrm{TiO}_{2}$. Appl. Catal. B 2008, 84, 332-339.

83. Teoh, W.Y.; Mädler, L.; Amal, R. Inter-Relationship between Pt Oxidation States on $\mathrm{TiO}_{2}$ and the Photocatalytic Mineralisation of Organic Matters. J. Catal. 2007, 251, 271-280.

84. Chiarello, G.L.; Aguirre, M.H.; Selli, E. Hydrogen Production by Photocatalytic Steam Reforming of Methanol on Noble Metal-Modified $\mathrm{TiO}_{2}$. J. Catal. 2010, 273, 182-190.

85. Chiarello, G.L.; Ferri, D.; Selli, E. Effect of the $\mathrm{CH}_{3} \mathrm{OH} / \mathrm{H}_{2} \mathrm{O}$ Ratio on the Mechanism of the Gas-Phase Photocatalytic Reforming of Methanol on Noble Metal-Modified $\mathrm{TiO}_{2}$. J. Catal. 2011, 280, 168-177.

86. Hou, W.; Cronin, S.B. A Review of Surface Plasmon Resonance-Enhanced Photocatalysis. Adv. Funct. Mater. 2013, 23, 1612-1619.

(C) 2013 by the authors; licensee MDPI, Basel, Switzerland. This article is an open access article distributed under the terms and conditions of the Creative Commons Attribution license (http://creativecommons.org/licenses/by/3.0/). 